\title{
A Novel Nonenzymatic Hydrogen Peroxide Sensor Based on a Polypyrrole Nanowire-Copper Nanocomposite Modified Gold Electrode
}

\section{Tingting Zhang, Ruo Yuan *, Yaqin. Chai, Wenjuan Li and Shujuan Ling}

Chongqing Key Laboratory of Analytical Chemistry, College of Chemistry and Chemical Engineering, Southwest University, key Laboratory on Luminescence and Real-Time Analysis Southwest University, Ministry of Education, Chongqing 400715, P.R. China; E-Mails: ztt8208@swu.edu.cn (T.T.Z.); yqchai@swu.edu.cn (Y.Q.C); ruyue@swu.edu.cn (W.J.L); 1sj0832@ swu.edu.cn (S.J.L)

* Author to whom correspondence should be addressed: yuanruo@swu.edu.cn. (R.Y); Tel.: 02368252277; Fax: 023-68254000

Received: 10 July 2008; in revised form: 19 August 2008 / Accepted: 20 August 2008 /

Published: 28 August 2008

\begin{abstract}
A novel nonenzymatic hydrogen peroxide $\left(\mathrm{H}_{2} \mathrm{O}_{2}\right)$ sensor has been fabricated by dispersing copper nanoparticles onto polypyrrole (PPy) nanowires by cyclic voltammetry (CV) to form PPy-copper nanocomposites on gold electrodes. Scanning electron microscopy (SEM) was used to characterize the morphologies of the PPy nanowires and the PPy-copper nanocomposite. The reactivity of the PPy-copper nanocomposite towards $\mathrm{H}_{2} \mathrm{O}_{2}$ was characterized by cyclic voltammetry and chronoamperometry. Effects of applied potential, the concentrations of detection solution upon the response currents of the sensor were investigated for an optimum analytical performance. It was proved that the PPy-copper nanocomposite showed excellent catalytic activity for the reduction of hydrogen peroxide $\left(\mathrm{H}_{2} \mathrm{O}_{2}\right)$. The sensor showed a linear response to hydrogen peroxide in the concentration range between $7.0 \times 10^{-6}$ and $4.3 \times 10^{-3} \mathrm{~mol} \mathrm{~L}^{-1}$ with a high sensitivity, and a detection limit of $2.3 \times 10^{-6} \mathrm{~mol} \mathrm{~L}^{-1}$. Experiment results also showed that the sensor had good stability.
\end{abstract}

Keywords: Polypyrrole nanowires, Copper nanoparticles, Nonenzymatic sensor, Hydrogen peroxide 


\section{Introduction}

There is a need for economical, simple and reliable methods to detect hydrogen peroxide $\left(\mathrm{H}_{2} \mathrm{O}_{2}\right)$, because of its use in many research fields such as the food industry, biotechnology, the clinic, the pharmaceutical industry and environmental protection [1,3]. Many analytical methods have been reported for the determination of $\mathrm{H}_{2} \mathrm{O}_{2}$ [4], including spectrophotometry [5], chemiluminescence [6], and electrochemistry [7-9]. Among these methods, electrochemistry has become a subject of considerable interest because of its low detection limit, high selectivity and high sensitivity. Many of these biosensors were based on immobilization of a protein, such as horseradish peroxidase (HRP) [10], hemoglobin $(\mathrm{Hb})[11,12]$ and heme $[13,14]$ for detecting $\mathrm{H}_{2} \mathrm{O}_{2}$, but the ready denaturation of immobilized enzyme/protein on the surface of the electrode is a common problem which leads to such modified electrodes suffering from a poor enzyme/protein activity and low reproducibility and stability [15]. Considering these facts, there has been more and more interest in nonenzymatic sensors and the fabrication of nonenzymatic sensors, including electrodes modified with bismuth [16], carbon nanotubes [17] and conducting polymers [18] has been reported.

Pyrrole, as a key member within the organic conducting polymers family, has higher conductivity than many other conducting polymers such as polyaniline, as well as good environmental stability [19]. For these reasons it has attracted considerable attention and many articles have reported its applications in biosensors [20, 21]. PPy film could be further improved by embedding metal particles into the polymer matrix to form a metal-polymer composite [22, 23]. This polymer-metal nanocomposite can provide a highly porous structure with a large effective surface area, good electronic conductivity and high catalytic activity [24]. Some metal-polymer nanocomposites have already been reported in the literature, such as PPy/Au [25], PPy/Pt [26], PPy/Ag [27], PPy/Ti [28] and PPy/Pd nanocomposites [29].

PPy nanowires the subject of a great deal of interest because they offer more advantages than traditionally synthesized PPy films, such as their higher electronic conductivity, charge transport properties, well-ordered polymer chain structures with high surface-to-volume ratio and small cross dimensions [30]. Tian et al. have prepared PPy nanowires on electrode surfaces under stationary potentials by a template-free method to produce an enzymatic biosensor [31]. Li et al. have reported Pt nanoclusters embedded in PPy nanowires to fabricate glucose biosensors [24].

It is well known that the copper-based chemically modified electrodes have been used in fabricating sensors. A hydrogen peroxide biosensor is fabricated by using a DNA-Cu (II) complex as electrocatalyst [32]. Copper-dispersed polyaniline modified electrode is capable of oxidizing glucose in an alkaline hydroxide solution [33]. Glucose sensor is fabricated with a composite of copper nanocluster/multiwall carbon nanotube [34]. Dimethylglyoxime functionalized copper nanoparticles (DMG-CuNPs) were synthesized by a simple microwave irradiation method [35]. The characterization of polypyrrole film modified with copper nanoparticles has been analyzed by Cioffi [36], but there are no reports on the application of the nanocomposite of copper nanoparticles dispersed onto PPy nanowires to construct a hydrogen peroxide sensor.

In previous work, we have developed some biosensors based on multiwall carbon nanotube/gold nanoparticles and silver nanoparticles to immobilize $\mathrm{Hb}$ and HRP for detection hydrogen peroxide [37, 38]. This paper describes a simple and effective method to fabricate a nonenzymatic hydrogen 
peroxide sensor by catalytic reduction with electropolyrized copper nanoparticles on the electrode modified with PPy nanowires. Though lacking an enzyme film, the sensor exhibited excellent performance features, such as low detection limits, wide linear range, quick current response, high sensitivity and good stability. This may be due to the PPy-copper nanocomposite providing a large surface area, good electronic conductivity and high catalytic activity.

\section{Results and Discussion}

\subsection{Characterization of Electrode Surface}

The morphologies of PPy nanowires and PPy-copper nanocomposite were investigated by scanning electron microscopy (SEM). Figure 1(a) show the fibriform morphology PPy nanowires.The PPy nanowires film possessed gaps and pores, so it was easy for copper nanoparticles to disperse on the special structure film. Figure 1(b) shows the morphologies of the PPy-copper nanocomposite used in the experiment. When copper nanoparticles were polymerized on the PPy nanowires film, the PPy nanowires in Figure 1(b) was not clear enough due to that the nanowires were covered with copper nanoparticles.

Figure 1. SEM images of PPy nanowires (a) and PPy-copper nanocomposite surface (b) on gold electrode.
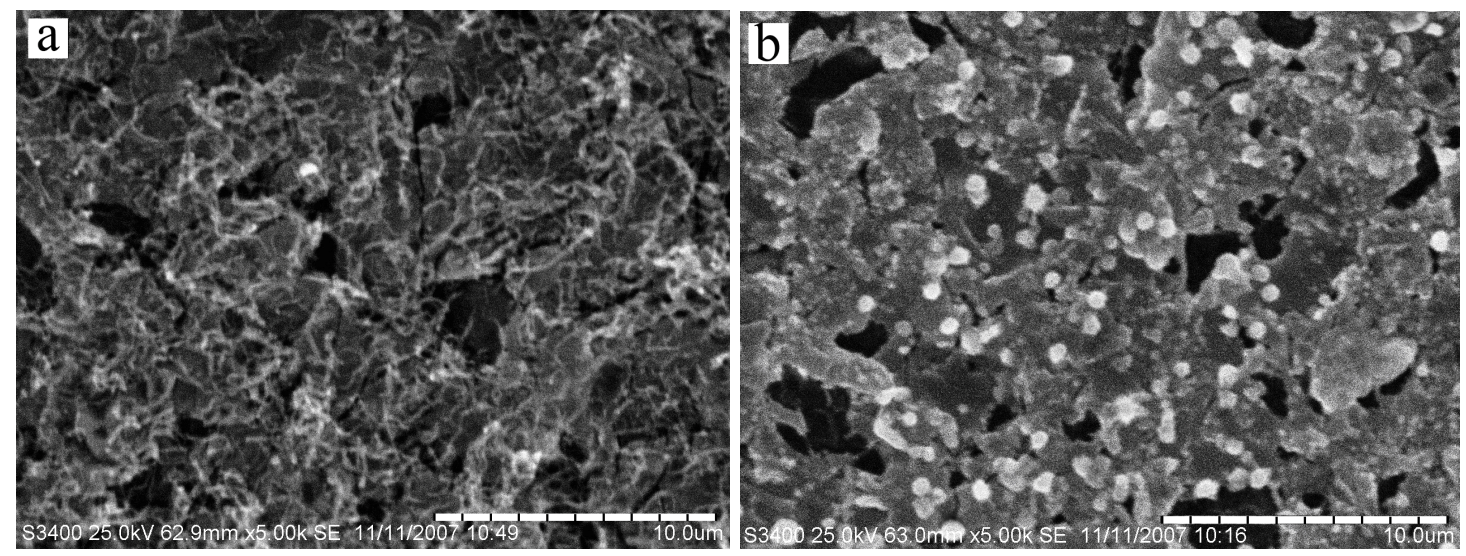

\subsection{Electrochemical Characterization of the Modified Electrode}

Cyclic voltammetry (CV) was useful in providing reliable chemical information of the electrode in alkaline solution. Figure 2 shows cyclic voltammograms of different modified electrodes in $\mathrm{NaOH}(0.1$ mol L ${ }^{-1}$ ) solution. Figure 2a shows the graph of a clean Au electrode surface. When the electrode was modified with PPy nanowires, no obvious peaks appeared (Figure 2b). After the electrode was modified with copper nanoparticles, two pairs of oxidation and reduction peaks were observed and the current was increased (Figure 2c). The anodic peaks labeled A at $-0.152 \mathrm{~V}$ represent the transition of $\mathrm{Cu}$ (I) to $\mathrm{Cu}$ (II), The anodic peaks labeled $\mathrm{B}$ at the $-0.378 \mathrm{~V}$ the formation of $\mathrm{Cu}$ (II) species due to oxidation of metallic $\mathrm{Cu}$ to $\mathrm{Cu}$ (II) and $\mathrm{Cu}$ (I) to $\mathrm{Cu}$ (II). The cathodic peaks labeled $\mathrm{C}$ at the $-0.345 \mathrm{~V}$ and $\mathrm{D}$ at the $-0.674 \mathrm{~V}$ correspond to the transition of $\mathrm{Cu}$ (II) to $\mathrm{Cu}(\mathrm{I}), \mathrm{Cu}$ (I) to $\mathrm{Cu}(0)$, respectively. 
These CV characteristies of the modified electrode were similar to that reported in the literatures [34, 35]. But, the peak potentials observed at the composite are slightly shifted in the positive direction.

Figure 2. Cyclic voltammograms of an $\mathrm{Au}$ electrode in $\mathrm{NaOH}\left(0.1 \mathrm{~mol} \mathrm{~L}^{-1}\right)$. (a) bare $\mathrm{Au}$ electrode, (b) PPy nanowires modified electrode and (c) PPy-copper nanocomposite modified electrode by sweeping at a scan rate of $100 \mathrm{mV} \mathrm{s}^{-1}$ in a $0.1 \mathrm{~mol} \mathrm{~L}^{-1} \mathrm{NaOH}$ solution.

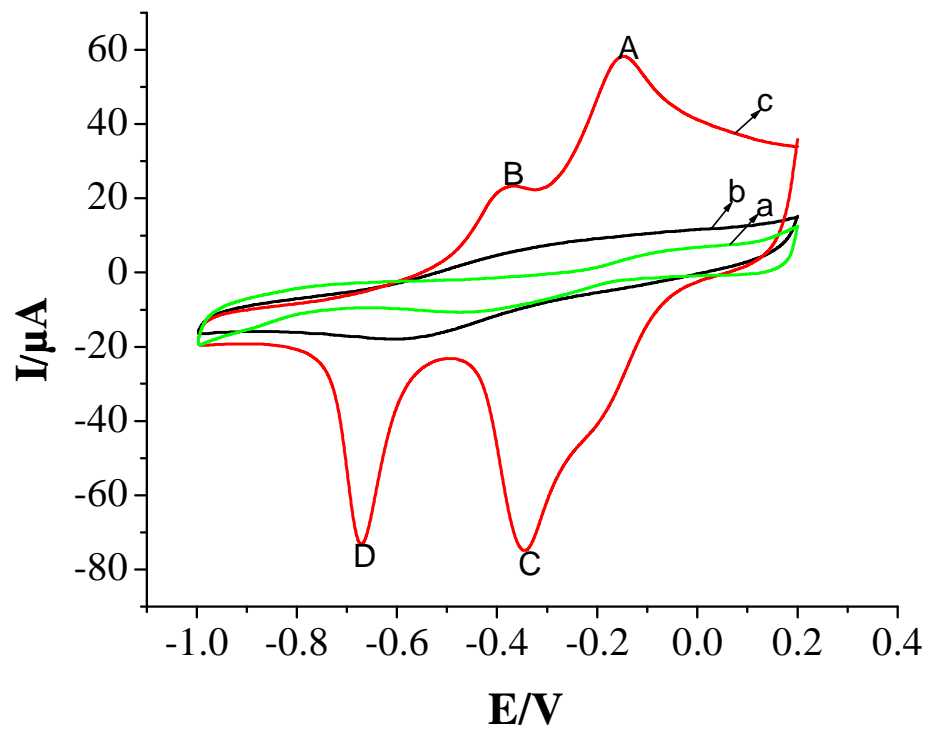

\subsection{Influence of Potential on Sensor Response}

In order to improve the performance of the sensor, factors which may influence the response of the sensor were studied. Figure 3 shows the dependence of the chronoamperometric current response to constant concentration $1.4 \times 10^{-5} \mathrm{~mol} \mathrm{~L}^{-1} \mathrm{H}_{2} \mathrm{O}_{2}$ on the applied potential in the range from $0 \mathrm{~V}$ to $-0.5 \mathrm{~V}$. As can be seen, the response current increased from 0 to $-0.35 \mathrm{~V}$. When the then potential is more negative than $-0.35 \mathrm{~V}$, the response current decreases slightly. To decrease the contribution from the most common interferents, a potential of $-0.3 \mathrm{~V}$ was choosen as work potential in all the subsequent amperometric detection.

\subsection{Optimization of the Concentration of $\mathrm{NaOH}$ for the Sensor}

To enhance the electrocatalytic activity of $\mathrm{PPy}-\mathrm{Cu}$ nanocomposite for hydrogen peroxide, an alkaline medium is required. When the concentrations of the $\mathrm{NaOH}$ were changed from $40 \mathrm{mmol} \mathrm{L}^{-1}$ to $100 \mathrm{mmol} \mathrm{L}^{-1}$, the response current was increased. But, when the concentrations of $\mathrm{NaOH}$ were above $100 \mathrm{mmol} \mathrm{L}^{-1}$, the response current was not improved with high background noise. In this experiment, $100 \mathrm{mmol} \mathrm{L}^{-1} \mathrm{NaOH}$ was choosen as the detection solution. 
Figure 3. Effect of the work potential to $\mathrm{PPy}-\mathrm{Cu}$ nanocomposite modified $\mathrm{Au}$ electrode in the presence of $1.4 \times 10^{-5} \mathrm{~mol} \mathrm{~L}^{-1} \mathrm{H}_{2} \mathrm{O}_{2}$. Applied potential: $-0.3 \mathrm{~V}$. Solution: $0.1 \mathrm{~mol} \mathrm{~L}^{-1}$ $\mathrm{NaOH}$.

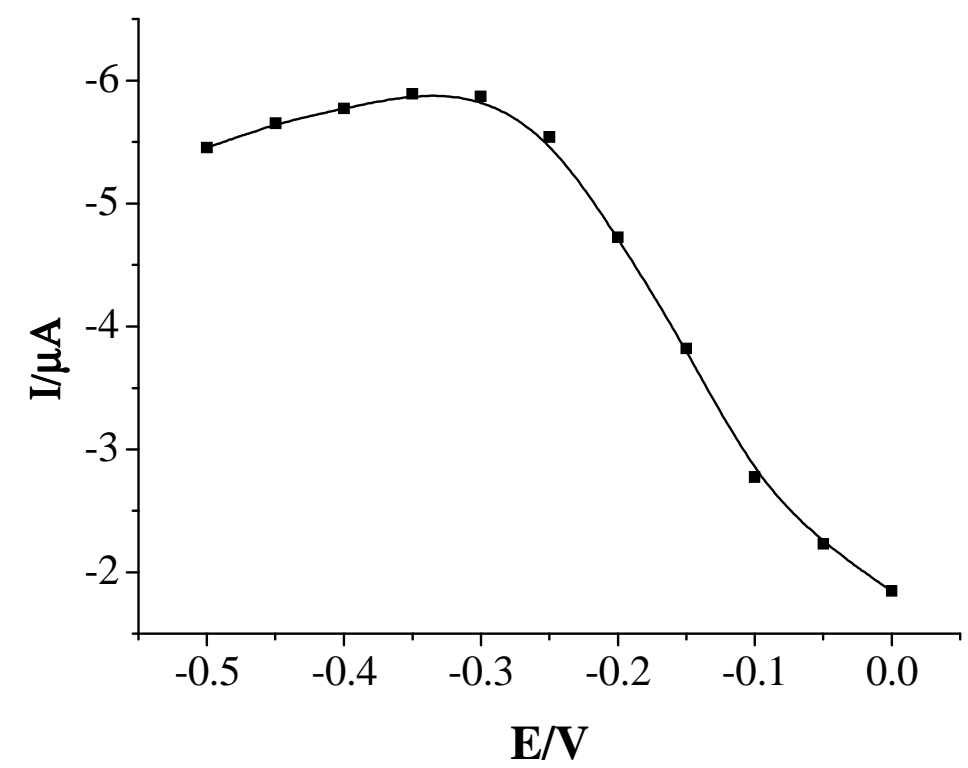

\subsection{The Sensor Response to Hydrogen Peroxide}

Figure 4 shows cyclic voltammograms of the PPy-copper nanocomposite modified Au electrode without and with different $\mathrm{H}_{2} \mathrm{O}_{2}$ concentration in the solution of $0.1 \mathrm{~mol} \mathrm{~L}^{-1} \mathrm{NaOH}$ at $100 \mathrm{mV} \mathrm{s}^{-1}$. In the absence of $\mathrm{H}_{2} \mathrm{O}_{2}$ a typical $\mathrm{PPy}-\mathrm{Cu}$ nanocomposite oxidation and reduction peak was observed (curve a). When $3.5 \times 10^{-5}$ mol L ${ }^{-1} \mathrm{H}_{2} \mathrm{O}_{2}$ was added to $\mathrm{NaOH}\left(0.1 \mathrm{mmol} \mathrm{L}{ }^{-1}\right)$ solution, an obvious increase of the cathodic peak current was observed (curve b), indicating that the $\mathrm{PPy}-\mathrm{Cu}$ nanocomposite showed good catalysis towards $\mathrm{H}_{2} \mathrm{O}_{2}$. With the addition of $\mathrm{H}_{2} \mathrm{O}_{2}$, the cathodic peak current increased significantly and the anodic peak current decreased obviously (curve b-d). It was observed that reduction peak current increased with the increasing concentration of $\mathrm{H}_{2} \mathrm{O}_{2}$. However, no catalytic current corresponding to the reduction of $\mathrm{H}_{2} \mathrm{O}_{2}$ can be observed at PPy nanowires modified electrode under the same condition, so it can be concluded that copper ion in the PPy-Cu nanocomposite is responsible for the reduction of $\mathrm{H}_{2} \mathrm{O}_{2}$. In a possible catalytic mechanism for the reduction of $\mathrm{H}_{2} \mathrm{O}_{2} \mathrm{Cu}$ (II) was first reduced electrochemically to $\mathrm{Cu}$ (I), which reacted chemically with $\mathrm{H}_{2} \mathrm{O}_{2}$ and resulted in the conversion of $\mathrm{H}_{2} \mathrm{O}_{2}$ into $\mathrm{OH}^{-}$and regeneration of the catalyst, as shown in the following equations:

$$
\begin{aligned}
& \mathrm{PPy} / \mathrm{Cu}(\mathrm{II})+\mathrm{e}^{-} \longrightarrow \mathrm{PPy} / \mathrm{Cu}(\mathrm{I})(1) \\
& \mathrm{PPy} / \mathrm{Cu}(\mathrm{I})+1 / 2 \mathrm{H}_{2} \mathrm{O}_{2} \rightarrow \mathrm{PPy} / \mathrm{Cu}(\mathrm{II})+\mathrm{OH}^{-}(2)
\end{aligned}
$$


Figure 4. Cyclic voltammograms of the Ppy-copper nanocomposite modified $\mathrm{Au}$ electrode in the presence of different $\mathrm{H}_{2} \mathrm{O}_{2}$ concentration in the solution of $0.1 \mathrm{~mol} \mathrm{~L}^{-1}$ $\mathrm{NaOH}$ at $100 \mathrm{mV} \mathrm{s}^{-1}$, (a) $0 \mathrm{~mol} \mathrm{~L}^{-1}$, (b) $3.5 \times 10^{-5} \mathrm{~mol} \mathrm{~L}^{-1}$, (c) $4.9 \times 10^{-4} \mathrm{~mol} \mathrm{~L}^{-1}$ and (d) $1.19 \times 10^{-3} \mathrm{~mol} \mathrm{~L}^{-1}$.

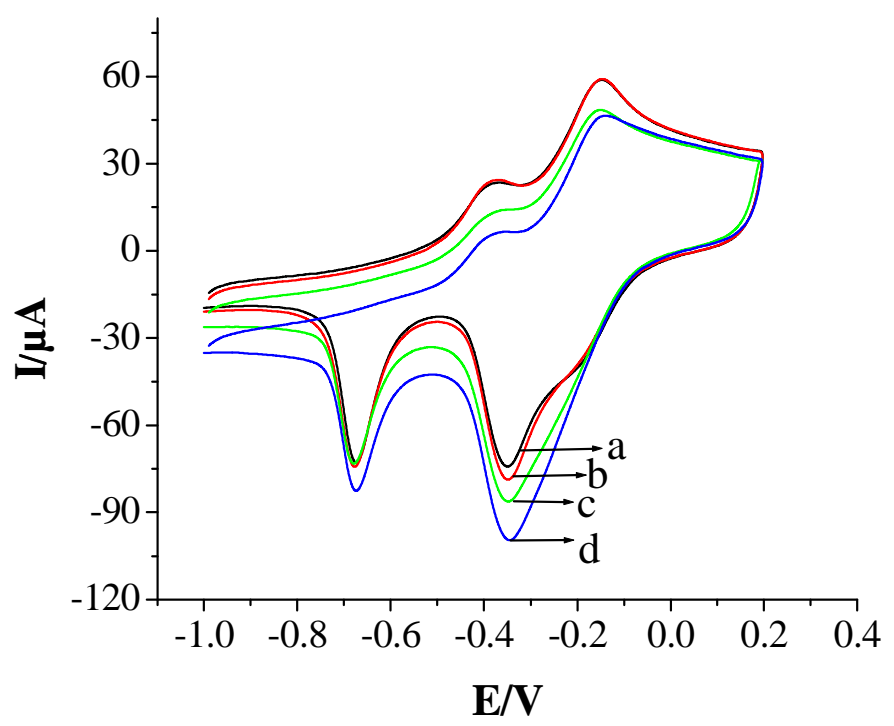

Figure 5 shows the amperometric response of the sensor under the optimized experiment conditions with successive addition of different concentrations of hydrogen peroxide in a stirred $0.1 \mathrm{~mol} \mathrm{~L}^{-1}$ $\mathrm{NaOH}$ solution.

Figure 5. Shows the typical current-time curves of the sensor under the applied potential of $-0.3 \mathrm{~V}$ with successive injection of $\mathrm{H}_{2} \mathrm{O}_{2}$ in a stirred $0.1 \mathrm{~mol} \mathrm{~L}^{-1} \mathrm{NaOH}$ solution. The injection of $\mathrm{H}_{2} \mathrm{O}_{2}$ concentration: (a) $7.0 \times 10^{-6} \mathrm{~mol} \mathrm{~L}^{-1}$, (b) $2.8 \times 10^{-5} \mathrm{~mol} \mathrm{~L}^{-1}$, (c) $9.8 \times 10^{-5}$ $\mathrm{mol} \mathrm{L}{ }^{-1}$ and (d) $4.48 \times 10^{-4} \mathrm{~mol} \mathrm{~L}^{-1}$. Inset shows linear calibration curves.

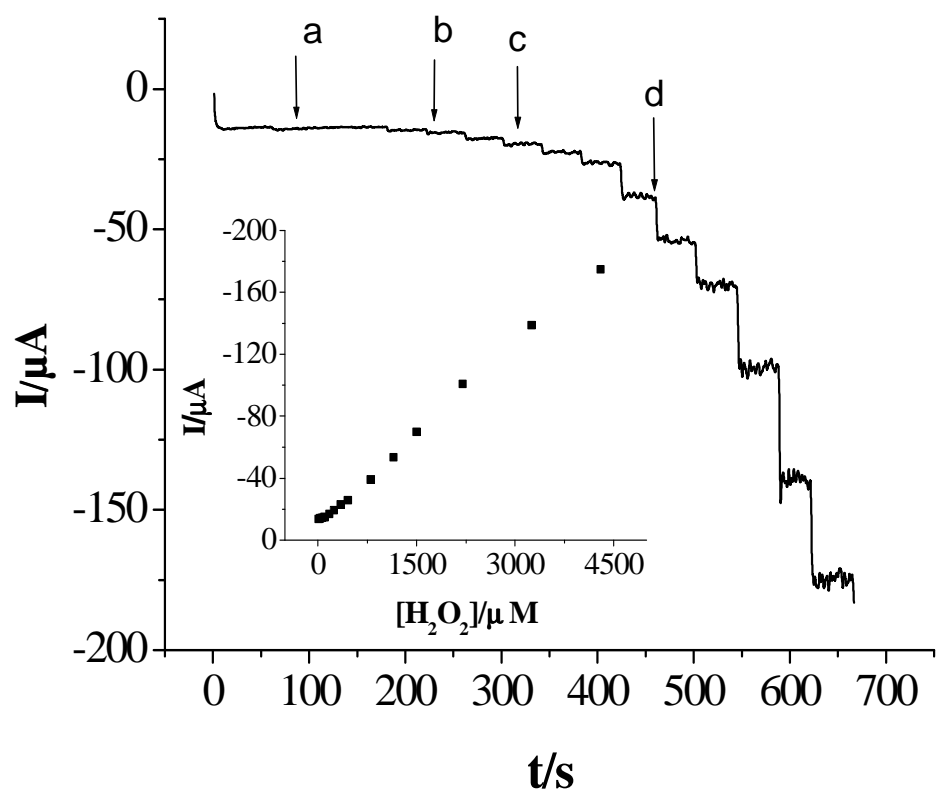


At an applied potential of $-0.3 \mathrm{~V}$, as the concentration of $\mathrm{H}_{2} \mathrm{O}_{2}$ increased the response current increased immediately and finally reached $95 \%$ of the steady-state value; a fast response time of $5 \mathrm{~s}$ was estimated. Such a fast response time may be attributed to fast diffusion of $\mathrm{H}_{2} \mathrm{O}_{2}$ within the PPycopper nanocomposite and excellent electron transfer behavior of copper within the PPy film on the gold electrode surface. We used the steady-state current to plot with the concentration of $\mathrm{H}_{2} \mathrm{O}_{2}$, as shown in the inset of Figure 5. The sensor displayed a linear range $\left(7.0 \times 10^{-6}\right.$ to $\left.4.3 \times 10^{-3} \mathrm{~mol} \mathrm{~L}^{-1} \mathrm{H}_{2} \mathrm{O}_{2}\right)$ with a correlation coefficient of 0.9981 , a detection limit of $2.3 \times 10^{-6} \mathrm{~mol} \mathrm{~L}^{-1}$ at signal-to-noise ration of 3. The good performance of the sensor may be attributed to the good electronic conductivity and high catalytic activity of the PPy-copper nanocomposite.

\subsection{Stability of the Hydrogen Peroxide Sensor}

In order to study the stability of the sensor, amperometric measurements were performed in the presence of $1.0 \times 10^{-4} \mathrm{~mol} \mathrm{~L}^{-1} \mathrm{H}_{2} \mathrm{O}_{2}$ periodically. When not in use, the electrode was stored at $4 \square$ in a refrigerator. After storage for 1 week, the response of the sensor was maintained about $93 \%$ of the initial values. The sensor still retained $85 \%$ of its original values after two weeks. The storage stability may be attributed to the stable film of the PPy-copper nanocomposite.

\subsection{Selectivity of the Hydrogen Peroxide Sensor}

Selectivity is another important factor which affects the performance of a sensor. In this experiment, five interfering substances (glucose, glycine, ethanol, acetic acid, and l-cysteine) were used to evaluate the selectivity of the sensor. The interference experiments were performed under optimum condition by comparing the current response to $0.2 \mathrm{mmol} \mathrm{L}^{-1} \mathrm{H}_{2} \mathrm{O}_{2}$ in the presence of $0.4 \mathrm{mM}$ of each interfering substance with that to $0.2 \mathrm{~m} \mathrm{~mol} \mathrm{~L}^{-1} \mathrm{H}_{2} \mathrm{O}_{2}$ alone. The results of the interference study are listed in Table 1, the tested substances did not interfere significantly with the resulting sensor.

Table 1. Possible interferences tested by the sensor.

\begin{tabular}{|c|c|}
\hline Interfering reagent & Current ratio $^{\text {a,b }}$ \\
\hline glucose & 1.02 \\
glycine & 1.01 \\
ethanol & 1.01 \\
acetic acid & 0.99 \\
l-cysteine & 0.96 \\
\hline
\end{tabular}

${ }^{a}$ Ratio of currents for mixtures containing $0.4 \mathrm{mmol} \mathrm{L}^{-1}$ interfering substance and $0.2 \mathrm{mmol} \mathrm{L}^{-1} \mathrm{H}_{2} \mathrm{O}_{2}$ to that for $0.2 \mathrm{mmol} \mathrm{L}^{-1} \mathrm{H}_{2} \mathrm{O}_{2}$ alone. ${ }^{\mathrm{b}}$ Average values from three successive determinations. 


\subsection{Recovery Experiment}

The application of the sensor was evaluated through detecting recovery. Table 2. shows the recovery of three samples of different $\mathrm{H}_{2} \mathrm{O}_{2}$ concentrations which were derived by standard addition method, the recovery rate between $96.8 \%$ and $105 \%$.

Table 2. The recovery of different $\mathrm{H}_{2} \mathrm{O}_{2}$ concentrations in samples tested by the sensor.

\begin{tabular}{|c|c|c|c|}
\hline $\begin{array}{c}\text { Sample } \mathbf{H}_{\mathbf{2}} \mathbf{O}_{\mathbf{2}} \\
\left(\mathbf{m m o l ~ L}^{\mathbf{- 1}}\right)\end{array}$ & $\begin{array}{c}\text { Added } \mathbf{H}_{\mathbf{2}} \mathbf{O}_{\mathbf{2}} \\
\left(\mathbf{m m o l ~ L}^{-\mathbf{1}}\right)\end{array}$ & $\begin{array}{c}\text { Detected } \mathbf{H}_{\mathbf{2}} \mathbf{O}_{\mathbf{2}} \\
\left(\mathbf{m m o l ~ \mathbf { L } ^ { - 1 }}\right)\end{array}$ & $\begin{array}{c}\text { Recovery } \\
(\boldsymbol{\%})\end{array}$ \\
\hline 0.08 & 0.024 & 0.106 & 101.9 \\
0.4 & 0.35 & 0.726 & 96.8 \\
1.2 & 0.4 & 1.68 & 105 \\
\hline
\end{tabular}

\section{Experimental Section}

\subsection{Reagents}

Pyrrole was obtained from Shanghai Chemical Reagent Factory and purified twice by distillation under high purity nitrogen and then kept in a refrigerator before use. $\mathrm{CuSO}_{4} \cdot 5 \mathrm{H}_{2} \mathrm{O}$ was purchased from Chongqing Chemical Reagent Factory. Hydrogen peroxide (30\% w/v solution) was obtained from Chemical Reagent Company, Chongqing, China. The concentration of the more diluted hydrogen peroxide solutions prepared from $30 \%$ hydrogen peroxide was determined by titration with potassium permanganate. The solutions of various concentrations of $\mathrm{NaOH}$ were prepared for the study. All other Chemicals were of analytical-reagent grade and used without further purification. Doubly distilled water and high purity $\mathrm{N}_{2}$ were used.

\subsection{Apparatus and Chemicals}

Electrochemical measurements were carried out on CHI 660A electrochemical workstation (CHI instruments, Chenhua Corp, Shanghai, China). The scanning electron micrographs were taken with a scanning electron microscope (SEM, S-3400, Japan) at an acceleration voltage of $25 \mathrm{kV}$. A conventional three electrode system was employed with a modified Au electrode as a working electrode, a saturated calomel electrode (SCE) as a reference electrode, and a platinum wire as an auxiliary electrode. All the potentials given in this paper were referred to the SCE. The experimental solutions were deaerated by highly pure nitrogen for $10 \mathrm{~min}$. All the electrochemical experiments were carried out at room temperament.

\subsection{The modification of the Electrode}

The bare Au electrode was polished successively with $0.3 \mu \mathrm{m}$ and $0.05 \mu \mathrm{m}$ alumina before modification, and sonicated in double distilled, acetone and double distilled water for $5 \mathrm{~min}$, in order to remove any adsorbed substances on the electrode surface. The PPy-copper nanocomposite was formed 
in a two-step procedure. In the first stage, The PPy nanowire was electrochemically deposited at a constant potential of $0.80 \mathrm{~V}$ for $120 \mathrm{~s}$ in an aqueous solution of $0.1 \mathrm{~mol} \mathrm{~L}^{-1} \mathrm{LiClO}_{4}$ and $0.1 \mathrm{~mol} \mathrm{~L}^{-1}$ carbonate containing $0.15 \mathrm{~mol} \mathrm{~L}^{-1}$ pyrrole. The electrode was then put into $0.1 \mathrm{~mol} \mathrm{~L}^{-1} \mathrm{HClO}_{4}$ solution for $12 \mathrm{~h}$ to remove any carbonate ions to obtain the PPy nanowires modified electrode [31]. The second stage, the PPy nanowires modified electrode was immersed in the mixed solution of $0.1 \mathrm{~mol} \mathrm{~L}^{-1}$ $\mathrm{Na}_{2} \mathrm{SO}_{4}$ and $20 \mathrm{mmol} \mathrm{L}^{-1} \mathrm{CuSO}_{4}$ which was deoxygenated by high purity nitrogen for $10 \mathrm{~min}$ and conditioned by cyclic sweeping between $-0.40 \mathrm{~V}$ to $0.80 \mathrm{~V}$ at $100 \mathrm{mV} \mathrm{s}^{-1}$ for 30 cycles to obtain the PPy nanowires-copper nanoparticles modified electrode [33, 34]. The fabricated procedure of the sensor was shown in Scheme 1.

Scheme 1. The stepwise fabrication processes of the modified electrode.

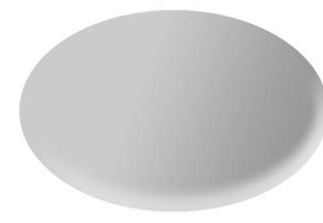

$\mathrm{Au}$

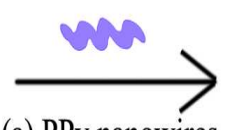

(a) PPy nanowires
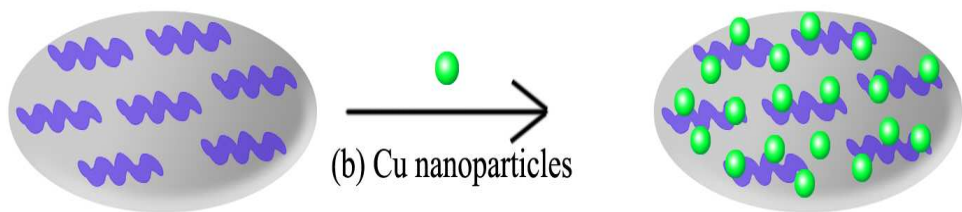

\section{Conclusions}

In this paper, a novel nonenzyme hydrogen peroxide biosensor was fabricated by using PPy-copper nanocomposite as a catalyst for the reduction of hydrogen peroxide. It proved that the PPy-copper nanocomposite showed excellent catalysis towards hydrogen peroxide in alkaline media and the sensor showed excellent performances, such as low detection limit, wide linear range, quick current response, high current and good stability. This nonenzyme system also overcame disadvantages of enzyme based biosensor.

\section{Acknowledgements}

This work was supported by the National Natural Science Foundation of China (No.20675064), the Natural Science Foundation of Chongqing City (CSTC-2004BB4149 and 2005BB4100) and the High Technology Project Foundation of Southwest University (XSGX 02), China. Chongqing Municipal Key Laboratory on Luminescence and Real-Time Analysis, Southwest University.

\section{References and Notes}

1. Bartlett, P.N.; Birkin, P.R.; Wang, J.H.; Palmisano, F.; Benedetto, G.D. An enzyme switch employing direct electrochemical communication between horseradish peroxidase and a poly (aniline) film. Anal. Chem. 1998, 70, 3685-3694.

2. Wang, J.; Lin, Y.H.; Chen, L. Organic-phase biosensor for monitoring phenol and hydrogen peroxide in pharmaceutical antibacterial products. Analyst 1993, 118, 277-280.

3. Sellers, R.M. Spectropohotometric determination of hydrogen peroxide using potassium titanium (IV) oxalate. Analyst 1980, 105, 950-954. 
4. Nakabayashi, Y.; Yoshikawa, H. Amperometric Biosensors for Sensing of Hydrogen Peroxide Based on Electron Transfer between Horseradish Peroxidase and Ferrocene as a Mediator. Anal. Sci. 2000, 16, 609-614.

5. Matsubara, C.; Kawamoto, N.; Takamura, K. Oxo[5,10,15,20-tetra (4-pyridyl)porphyrinato] titanium (IV): an ultra-high sensitivity spectrophotometric reagent for hydrogen peroxide. Analyst 1992, 117, 1781-1784.

6. Hanaoka, S.; Lin, J.M.; Yamada, M. Chemiluminescent flow sensor for $\mathrm{H}_{2} \mathrm{O}_{2}$ based on the decomposition of $\mathrm{H}_{2} \mathrm{O}_{2}$ catalyzed by cobalt (II)-ethanolamine complex immobilized on resin. Anal. Chim. Acta 2001, 426, 57-64.

7. Li, J.; Tan, S.N.; Ge, H.L. Silica sol-gel immobilized amperometric biosensor for hydrogen peroxide. Anal. Chim. Acta 1996, 335, 137-145.

8. Garguilo, M.G.; Huynh, N.; Proctor, A.; Michael, A.C. Amperometric sensors for peroxide, choline, and acetylcholine based on electron transfer between horseradish peroxidase and a redox polymer. Anal. Chem. 1993, 65, 523-528.

9. Xiao, Y.; Ju, H.X.; Chen, H.Y. A reagentless hydrogen peroxide sensor based on incorporation of horseradish peroxidase in poly (thionine) film on a monolayer modified electrode. Anal. Chim. Acta 1999, 391, 299-306.

10. Xiao, Y.; Ju, H.X.; Chen, H.Y. Direct electrochemistry of horseradish peroxidase immobilized on a colloid/cysteamine-modified gold electrode. Anal. Biochem. 2000, 278, 22-28.

11. Zhang, J.D.; Oyama, M. A hydrogen peroxide sensor based on the peroxidase activity of hemoglobin immobilized on gold nanoparticles-modified ITO electrode. Electrochim. Acta 2004, 50, 85-90.

12. Wang, Q.L.; Lu, G.X.; Yang, B.J. Hydrogen peroxide biosensor based on direct electrochemistry of hemoglobin immobilized on carbon paste electrode by a silica sol-gel film. Sens. Actuat. B 2004, 99, 50-57.

13. Liu, X.J.; Chen, T.; Liu, L.F.; Li, G.X. Electrochemical characteristics of heme proteins in hydroxyethylcellulose film, Sens. Actuators B 2006, 11, 106-111.

14. Feng, J.J.; Zhao, G.; Xu, J.J.; Chen, H.Y., Direct electrochemistry and electrocatalysis of heme proteins immobilized on gold nanoparticles stabilized by chitosan. Anal. Biochem. 2005, 34, 2280-2286.

15. Yang, Y.; Mu, S. Bioelectrochemical responses of the polyaniline horseradish peroxidase electrodes. J. Electroanal. Chem 1997, 432, 71-78.

16. Wittstock, G.; Strubing, A.; Szargan, R.; Werner, G. Glucose oxidation at bismuth-modified platinum electrodes. J. Electroanal. Chem. 1998, 444, 61-73.

17. Fumiyo, K.; Satoshi, K. Electrocatalytic activity of bamboo-Structured carbon nanotubes paste electrode toward hydrogen peroxide. Anal. Lett 2006, 39, 903-911.

18. Lu, Q.; Zhou, T.; Hu, S.S. Direct electrochemistry of hemoglobin in PHEA and its catalysis to $\mathrm{H}_{2} \mathrm{O}_{2}$. Biosens. Bioelectron 2007, 22, 899-904.

19. Ashwell, G.J. Molecular Electronics. John Wiley and Sons Ltd: New York, 1992.

20. Shin, M.C.; Kim, H.S. Effects of enzyme concentration and film thickness on the analytical performance of a polypyrrole/glucose oxidase biosensor. Anal. Lett 1995, 28, 1017-1031. 
21. Fiorito, P. A.; Brett, C.M.A.; Torresi, S.C. Polypyrrole/copper hexacyanoferrate hybrid as redox mediator for glucose biosensors. Talanta 2006, 69, 403-408.

22. Strike, D. J.; Rooij, N. F. D.; Koudelka-Hep, M.; Ulmann, M.; Augustynski, J. Electrocatalytic oxidation of methanol on platinum microparticles in polypyrrole. J. Appl. Electrochem. 1992, 22, 922-926.

23. Rau, J.R.; Chen, S.C.; Sun, H.W. Characterization of a polypyrrole microsensor for nitrate and nitrite ions. Electrochim. Acta 1994, 39, 2773-2779.

24. Li, J.; Lin, X.Q. Glocose biosensor based on immobilization of glucose oxidase in poly(oaminophenol) film on polypyrrole-Pt nanocomposite modified glassy carbon electrode. Biosens. Bioelectron 2007, 22, 2898-2905.

25. Chen, W.; Li, C.M. Electrosynthesis and characterization of polypyrrole/Au nanocomposite. Electrochim. Acta 2007, 52, 2845-2845.

26. Bose, C.S.C.; Rajeshwar, K. Efficient electrocatalyst assemblies for proton and oxygen reduction: the electrosynthesis and characterization of polypyrrole films containing nanodispersed platinum particle., J. Electroanal. Chem. 1992, 333, 235-256.

27. Liu, Y.C.; Lee, H.T.; Yang, S.J. Strategy for the syntheses of isolated fine silver nanoparticles and polypyrrole/silver nanocomposites on gold substrates. Electrochim. Acta 2006, 51, 3441-3445.

28. Roux, S.; Soler-Illia, G.J., Champagne, S., Audebert, P., Sanchez, C. Titania /Polypyrrole Hybrid Nanocomposites Built from In-Situ Generated Organically Functionalized Nanoanatase Building Blocks. Adv. Mater. 2003, 15, 217-221.

29. Cioffi, N.; Torsi, L.; Losito, I.; Franco, C. D.; Bari, I.D.; Chiavarone, L.; Scamarcio, G.; Tsakova, V.; Sabbatini, L.; Zambonin, P.G. Electrosynthesis and analytical characterization of polypyrrole thin films modified with copper nanoparticles. J. Mater. Chem. 2001, 11, 1434-1440.

30. Li, J.; Lin, X.Q. Electrocatalytic reduction of nitrite at polypyrrole nanowire- platinum nanocluster modified glassy carbon electrode. Microchem. J. 2007, 87, 41-46.

31. Tian, Y.; Wang, J.X.; Wang, Z.; Wang, S.C. Solid-phase extraction and amperometric determination of nitrite with polypyrrole nanowire modified electrodes. Sens. Actuat. B 2005, 104, 23-28.

32. Gu, T.T.; Hasebe, Y. DNA-Cu (II) poly(amine) complex membrane as novel catalytic layer for highly sensitive amperometric determination of hydrogen peroxide. Biosens. Bioelectron 2006, 21, 2121-2128.

33. Farrell, S. T.; Breslin, C. B. Oxidation and photo-induced oxidation of glucose at a polyaniline film modified by copper particles. Electrochim. Acta 2004, 49, 4497-4503.

34. Kang, X.H.; Mai, Z.B.; Zou, X.Y.; Cai, P.X.; Mo, J.Y. A sensitive nonenzymatic glucose sensor in alkaline media with a copper nanocluster/multiwall carbon nanotube-modified glassy carbon electrode. Anal. Bioanalytical. Chem. 2007, 363, 143-150.

35. Xu, Q.; Zhao, Y.; Xu, J.Z. Preparation of functionalized copper nanoparticles and fabrication of a glucose sensor. Sens. Actuat. B 2006, 114, 379-386.

36. Cioffi, N.; Torsi, L.; Sabbatini, L.; Zambonin, P.G.; Bleve-Zacheo, T. Electrosynthesis and characterisation of nanostructured palladium-polypyrrole composites. J. Electroanal.Chem. 2000, $488,42-47$. 
37. Chen, S.H.; Yuan, R.; Chai, Y.Q.; Zhang, L.Y.; Wang, N.; Li, X.L. Amperometric thirdgeneration hydrogen peroxide biosensor based on the immobilization of hemoglobin on multiwall carbon nanotubes and gold colloidal nanoparticles. Biosens. Bioelectron. 2007, 22, 1268-1274.

38. Wang, F.C.; Yuan, R.; Chai, Y.Q.; Tang, D.P. Probing traces of hydrogen peroxide by use of a biosensor based on mediator-free DNA and horseradish peroxidase immobilized on silver nanoparticles. Anal. Bioanal. Chem. 2007, 387, 709-717.

(C) 2008 by the authors; licensee Molecular Diversity Preservation International, Basel, Switzerland. This article is an open-access article distributed under the terms and conditions of the Creative Commons Attribution license (http://creativecommons.org/licenses/by/3.0/). 